\title{
Musculoskeletal dysfunction in dental practice
}

\author{
Hakim A. Larbi and Dmitry Ye. Suyetenkov
}

Saratov State Medical University, Saratov, Russia

Accepted 16 May 2012

Original Russian Text (C) Larbi HA, Suyetenkov DYe, 2011, published in Saratov Journal of Medical Scientific Research 2011; 7(1): $256-259$.

Abstract: This article highlights the comparative statistics of musculoskeletal system deseases depending on a type of dental method. The practical recommendations on prevention of diseases of joints, ligaments and spine were done.

Keywords: working positions of the dentist, prevention of arthritis, tendonitis.

Cite as Larbi HA, Suyetenkov DYe. Musculoskeletal dysfunction in dental practice. Russian Open Medical Journal 2012; 1: 0105.

Correspondence to Hakim Larbi. Address: 112, B.Kazachaya str., Saratov, 410012, Russia. E-mail: hakim05cd@yahoo.fr

\section{Introduction}

Dentist's work is heavy and hard. Interesting work often completely fascinates a doctor, but at the same time it is challenging. In dentist's practice there are subconscious violations of labor which cause undesirable consequences. In this case the doctor's health is endangered. From year to year minor deviations from normal work conditions accumulate and lead to consequences that make dentists' professional activity difficult or impossible [1-7].

The aim of this study: To study the effects of a dentist's position on the musculoskeletal system during the service of patients depending on age, sex and length of practice.

\section{Material and Methods}

More than a hundred of dentists from dental clinics of Saratov State Medical University (Saratov, Russia), municipal and private clinics of Saratov were interviewed. There were $66 \%$ female and $34 \%$ male.

They were suggested to answer the following questions: In the course of filling out the questionnaire it was necessary to answer the following questions: sex, age, work experience, specialization, the presence of diseases of the musculoskeletal system developed as a result of professional activities in the workplace.

\section{Results}

Findings of the interview are presented in tables and figures (tables 1-5, figures 1-5).

Table 1. Distribution of dentists according to their position by the dentist's chair during a service of patients, \%)

\begin{tabular}{cccccccc}
\hline Position of a dentist & $7 \mathrm{~h}$ & $8 \mathrm{~h}$ & $9 \mathrm{~h}$ & $10 \mathrm{~h}$ & $11 \mathrm{~h}$ & $12 \mathrm{~h}$ & $1 \mathrm{~h}$ \\
\hline$\%$ & $19 \%$ & $33 \%$ & $17 \%$ & $8 \%$ & $8 \%$ & $13 \%$ & $2 \%$ \\
\hline
\end{tabular}

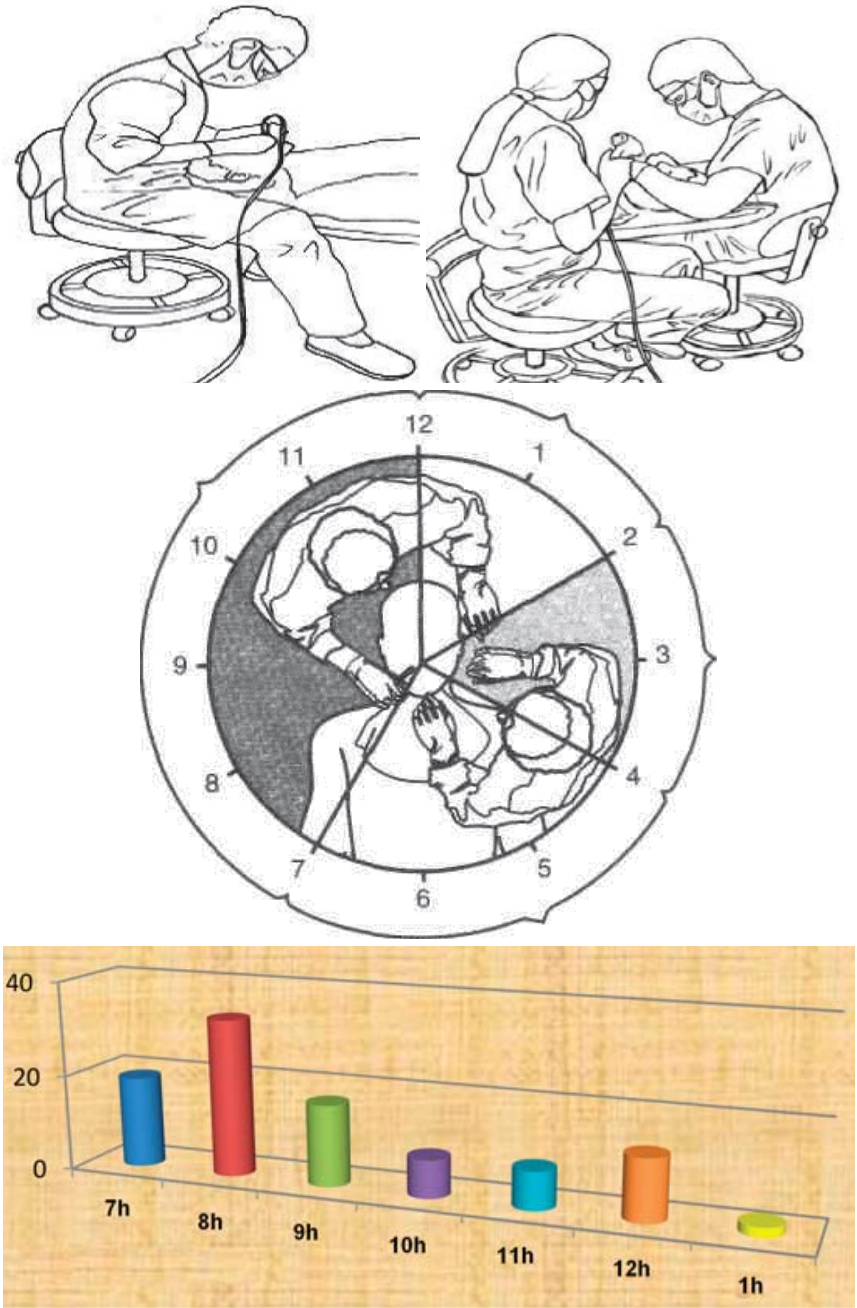

Figure 1. Distribution of dentists according to their position during operation. 
Table 2. Evidence of pain symptoms in different parts of the musculoskeletal system depending on the position of dentists during the service

\begin{tabular}{lcccccccc}
\hline $\begin{array}{l}\text { Parts of the } \\
\text { musculoskeletal }\end{array}$ & 7h & $\mathbf{8 h}$ & $\mathbf{9 h}$ & $\mathbf{1 0 h}$ & $\mathbf{1 1 h}$ & $\mathbf{1 2 h}$ & $\mathbf{1 h}$ \\
$\begin{array}{l}\text { system } \\
\text { Cervical spine }\end{array}$ & $18 \%$ & $37 \%$ & $19 \%$ & $7 \%$ & $7 \%$ & $10 \%$ & $2 \%$ \\
Thoracic spine & $21 \%$ & $39 \%$ & $20 \%$ & $3 \%$ & $6 \%$ & $11 \%$ & $3 \%$ \\
Lumbar spine & $26 \%$ & $33 \%$ & $14 \%$ & $3 \%$ & $11 \%$ & $11 \%$ & $2 \%$ \\
Wrist joint & $29 \%$ & $29 \%$ & $16 \%$ & $5 \%$ & $11 \%$ & $5 \%$ & $5 \%$ \\
Shoulder joint & $14 \%$ & $40 \%$ & $22 \%$ & $14 \%$ & $7 \%$ & $4 \%$ & $0 \%$ \\
\hline
\end{tabular}

Table 3. Evidence of pain symptoms of various parts of the musculoskeletal system depending on sex

\begin{tabular}{lccccc}
\hline & \multicolumn{4}{c}{ Parts of the musculoskeletal system } \\
& $\begin{array}{c}\text { Cervical } \\
\text { spine }\end{array}$ & $\begin{array}{c}\text { Thoracic } \\
\text { spine }\end{array}$ & $\begin{array}{c}\text { Lumbar } \\
\text { spine }\end{array}$ & $\begin{array}{c}\text { Wrist } \\
\text { joint }\end{array}$ & $\begin{array}{c}\text { Shoulder } \\
\text { joint }\end{array}$ \\
\hline Male & $38,5 \%$ & $28 \%$ & $32 \%$ & $18 \%$ & $40 \%$ \\
Female & $61,5 \%$ & $72 \%$ & $68 \%$ & $82 \%$ & $60 \%$ \\
\hline
\end{tabular}

Table 4. Evidence of pain symptoms of different parts in the musculoskeletal system depending on length of practice, $\%$

\begin{tabular}{lccccc}
\hline \multirow{2}{*}{$\begin{array}{l}\text { Parts of the } \\
\text { musculoskeletal }\end{array}$} & $\mathbf{1 - 5}$ & $\mathbf{6 - 1 0}$ & $\mathbf{1 1 - 1 5}$ & $\mathbf{1 6 - 2 0}$ & $\mathbf{2} 20$ \\
system & & & & & \\
\hline Cervical spine & $11 \%$ & $22 \%$ & $23 \%$ & $25 \%$ & $19 \%$ \\
Thoracic spine & $13 \%$ & $18 \%$ & $18 \%$ & $31 \%$ & $20 \%$ \\
Lumbar spine & $14 \%$ & $20 \%$ & $26 \%$ & $20 \%$ & $20 \%$ \\
Wrist joint & $5 \%$ & $14 \%$ & $23 \%$ & $27 \%$ & $32 \%$ \\
Shoulder joint & $7 \%$ & $28 \%$ & $10 \%$ & $34 \%$ & $21 \%$ \\
\hline
\end{tabular}

Table 5. Number of complaints of the condition of the musculoskeletal system for dentists in Constantine (Algeria), Saratov (Russia), Quebec (Canada)

\begin{tabular}{lccccc}
\hline City & \multicolumn{5}{c}{ Pain symptoms } \\
& $\begin{array}{c}\text { Cervical } \\
\text { part }\end{array}$ & Thoracic & Lumbar & $\begin{array}{c}\text { Radiocarpal } \\
\text { joint }\end{array}$ & $\begin{array}{c}\text { Soulder } \\
\text { joint }\end{array}$ \\
\hline Constantine & $11 \%$ & $15 \%$ & $17 \%$ & $4 \%$ & $82 \%$ \\
Saratov & $64 \%$ & $39 \%$ & $50 \%$ & $22 \%$ & $29 \%$ \\
Quebec & $27 \%$ & $22 \%$ & $23 \%$ & $9 \%$ & $25 \%$ \\
\hline
\end{tabular}

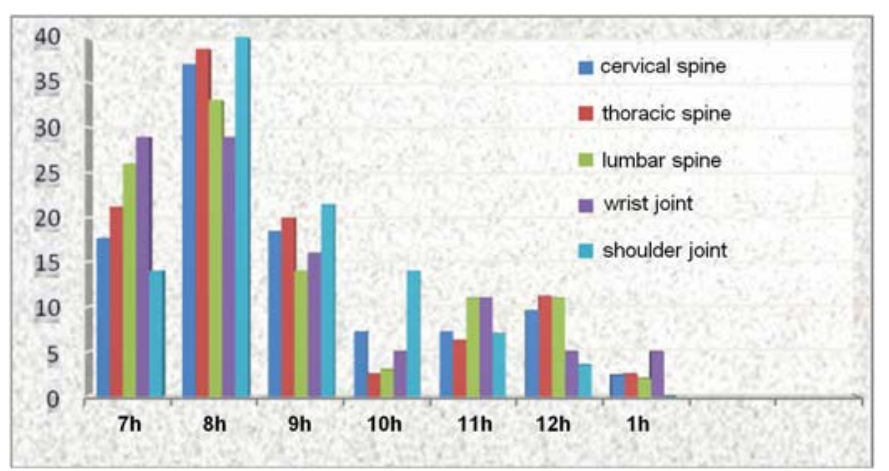

Figure 2. Evidence of pain symptoms in different parts of the musculoskeletal system depending on the position of dentists' during work.

According to these data we can conclude the following: the position of " $8 \mathrm{~h}$ " is used often, and the position of " $1 \mathrm{~h}$ " is used less. Positions "7h" is used 19\%, "9h" - 17\%, respectively, the position of "10h", "11 hours" and "12h" is still rarely used in comparison with "7h" and "9h".

Thus the position " $8 \mathrm{~h}$ " is the most harmful because all joints suffer from it. The safest positions are "11h", "12h", " $1 h$ " - big joints and spine are not hurt much.

That means that the most unfavorable position is " 8 hours", in this position affects all the joints. The safest position is "at 11,12 , 1 hour," in these positions large joints and spine are least affected.

On the ground of these data we can draw the following conclusion: women frequently suffer from wrist joint - in $82 \%$ of all cases, thoracic spine is damaged in a - $72 \%$ of cases, lumbar spine in $68 \%$. Men: shoulder joint - $40 \%$ of cases, cervical spine $-38.5 \%$ of cases, lumbar spine $-32 \%$ of cases.

Virtually every other dentist in the age of 45 knows by experience that the disorder of the locomotor system is the main pathology directly relates to the chosen specialty in youth.

If during the first 15 years of practice $10-15 \%$ of the dentists note arthropathy, so after $26-35$ years of practice it is found by $25-$ $45 \%$ of our colleagues [1].

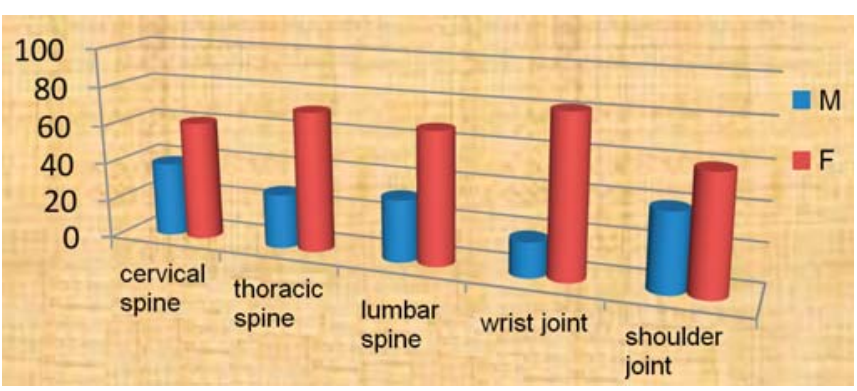

Figure 3. Evidence of pain symptoms in different parts of the musculoskeletal system depending on sex.

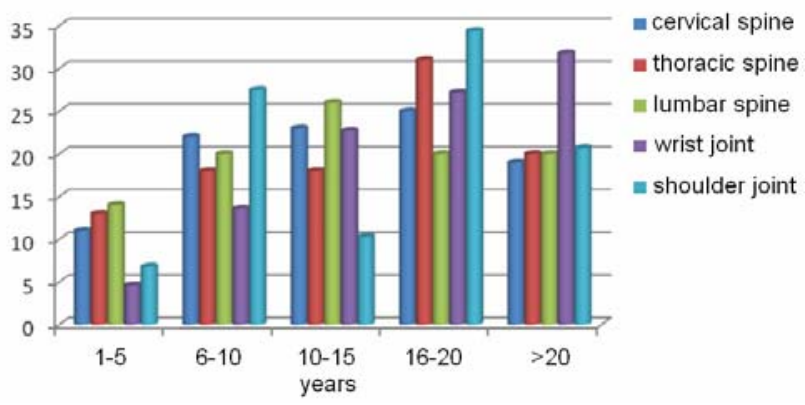

Figure 4. Evidence of pain symptoms in different parts of the musculoskeletal system depending on length of practice.

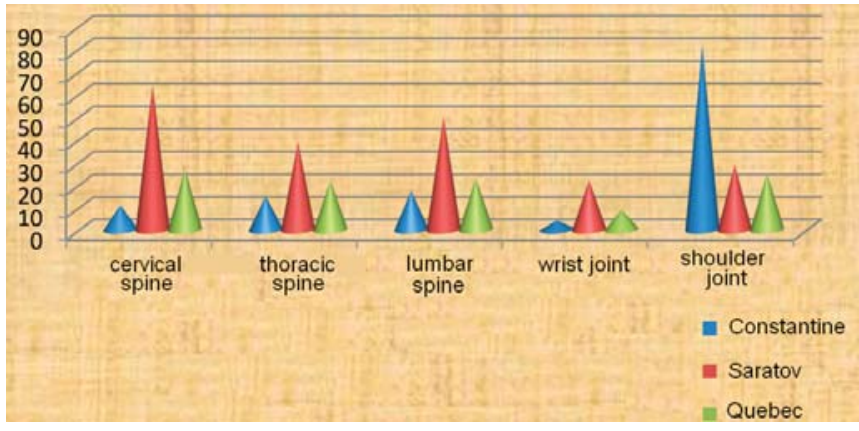

Figure 5. Amount of complaints of the condition of the musculoskeletal system for dentists in Constantine (Algeria), Saratov (Russia), Quebec (Canada). 
The main reasons of this are the wrong organization of the workplace, uncomfortable and crowded working posture, active repetitive actions that require some effort, and the absence of regularly organized rest. These circumstances deserve a special attention not only for the dentists but for every director as well. According to the U.S. Bureau of Labor Statistics disorders of the musculoskeletal system lead to more than $60 \%$ of all work-related injuries [2].

The rates of complains of the joints indicated above were compared in the towns where the research was held. The comparison reveals the influence of the different factors on the dentists' health in Russia, North Africa and American continent $[3,4]$. The predominance of affected spinal column among dentists working in Russia is certainly connected with the usual position of doctors "8-9h." This factor must be taken into consideration in the learning process in the dental faculties of universities. The gender, in our opinion, can only have a relative importance, but one cannot but admit a large proportion of women working in this sector of a public health service in Russia. The relatively large joint disorders of hands of doctors from other continents may be connected with some factors: the duration of the daily work, prevalence of mixed technique, predominance of men-doctors and different climatic and geographical factors as well $[5,6]$.

\section{Practical recommendations}

To eliminate undesirable musculoskeletal system load during the work the physician should try to keep "neutral" position $[1,2]$. Neutral position is an ideal location for a body when work activities are associated with a reduced risk of disorders of the musculoskeletal system. So as the body is a complex of its own parts, the neutral position is a complex of neutral positions which are optimal for the body. In general it is estimated that the more the body deviates from the neutral position and the longer to find the limb in this position, the greater the risk of diseases increasing.

It should be noted that the neutral position is a complex of neutral positions of individual parts of the body (Figures 6-12) [57].

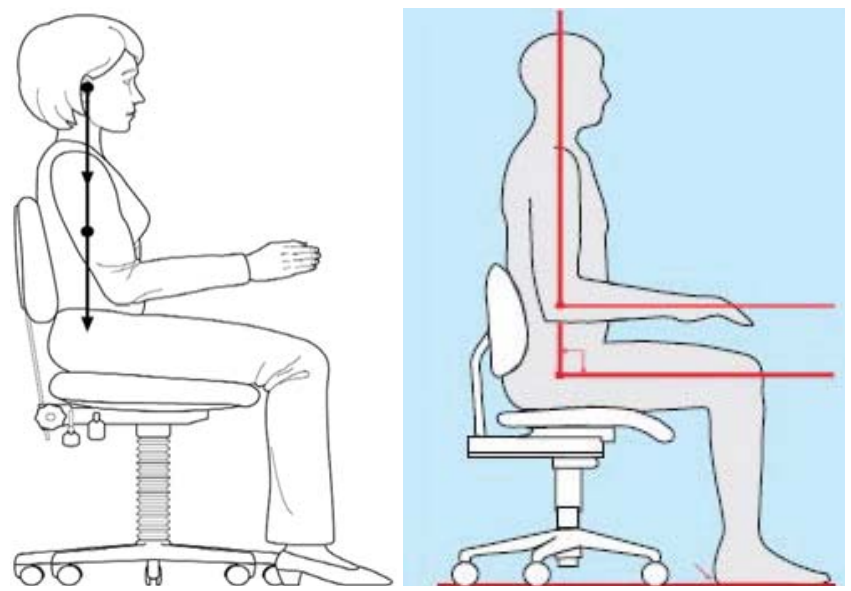

Figure 6. A sitting position is the neutral position for the body: the forearms are parallel to the floor, weight is balanced evenly; thighs are parallel to the floor, the angle between the torso and the thigh is $90^{\circ}$; the seat level is so low, as your heels can touch the ground.

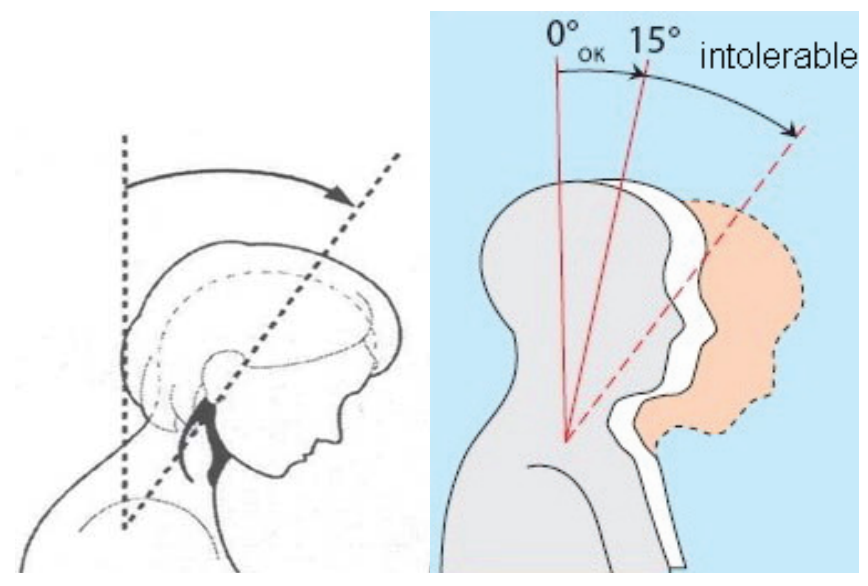

Figure 7. The neutral position for the neck: the head angle is $0-15^{\circ}$; the line between eyes the area of treatment must be as vertical as possible. Avoid tilting the head excessively forward or to one side.

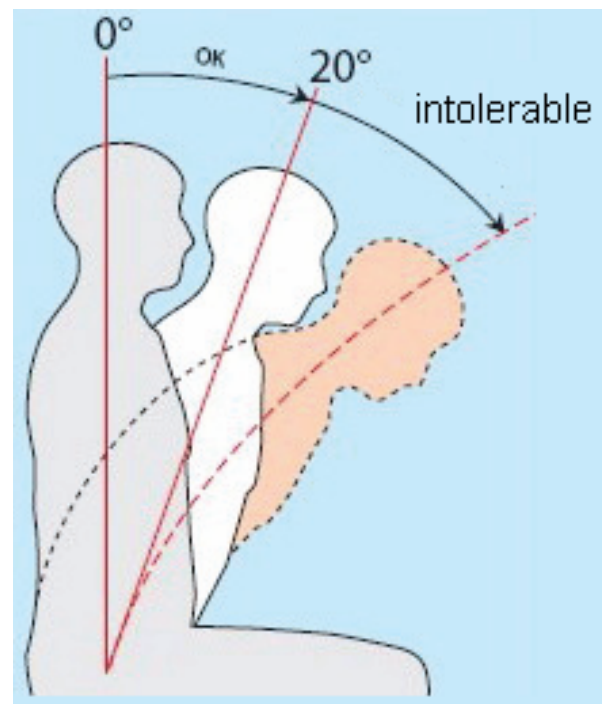

Figure 8. The neutral position for the body: bend the body slightly forward in the waist or hips area, the angle of inclination is $0^{\circ}-20^{\circ}$. Avoid excessive bending of the back.

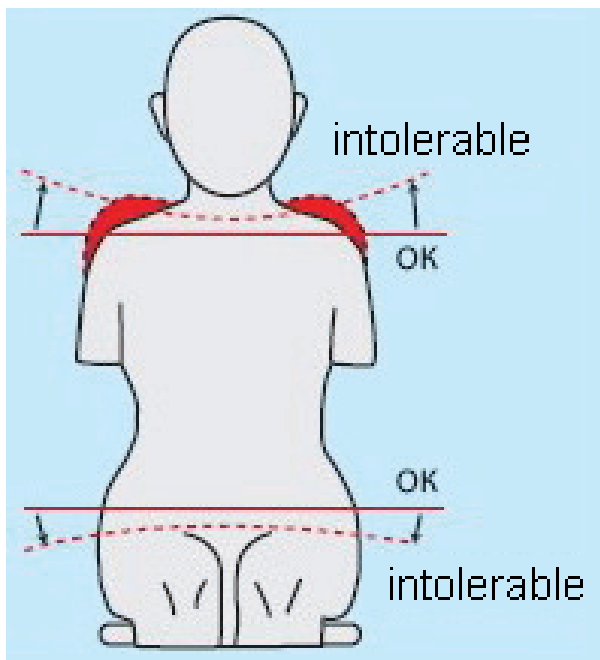

Figure 9. Neutral position: shoulders and hips are horizontal, weight is balanced evenly. Avoid positions in which the shoulders are raised up and displaced forward, and the body weight is distributed mainly on one hips. 


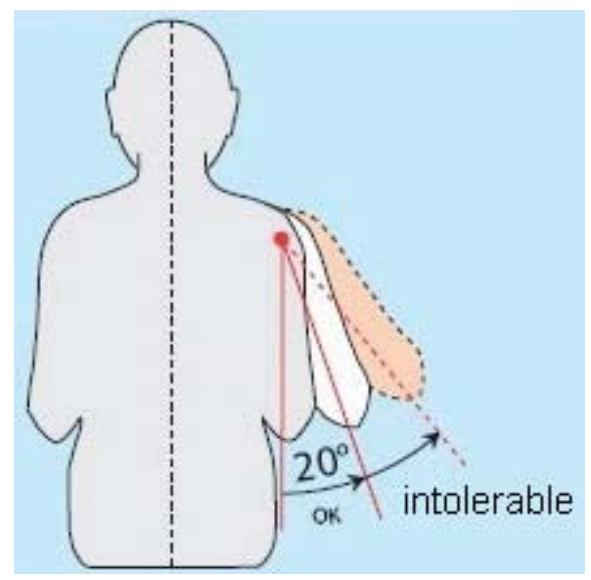

Figure 10. The neutral position for the hands: the hands are parallel to the long axis of the body, elbows are on waist level and maintained not far from body. Avoid the position when elbows are above the waist and shoulder deviations from the axis of the body is for more than $20^{\circ}$.

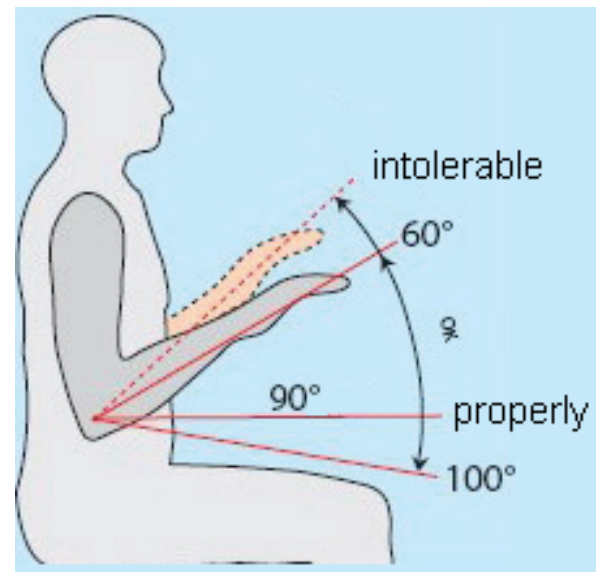

Figure 11. The neutral position for the forearm: forearms are parallel to the floor, rising or fall movement, if necessary, is made by bending the elbow. Avoid the bending the elbow joint when the angle between the forearm and the shoulder is less than $60^{\circ}$.

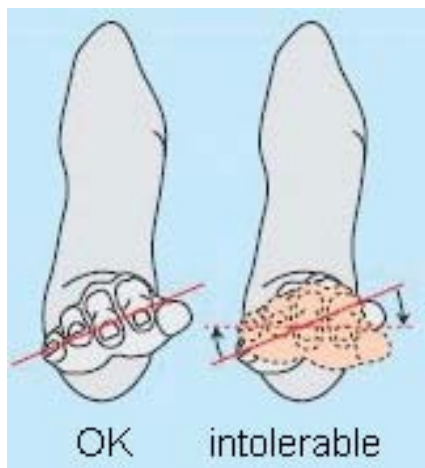

Figure 12. The neutral position for the hands: the little finger side of the hand is a little lower then the level of the thumb, the wrist is located on the same line with the forearm. Avoid lowering the side of your thumb so that the hand is parallel to the table, as well as to wrist and hand are to be bent down.

\section{Reference}

1. Guide de prévention des troubles musculo-squelettiques (TMS) en clinique dentaire. ASSTSAS, 2007: $276 \mathrm{p}$.
2. 1997 survey of current issues in dentistry: Repetitive motion injuries. Chicago: American Dental Association, 1998: $12 \mathrm{p}$.

3. Rundcrantz BL. Pain and discomfort in the musculoskeletal system among dentists. Swed Dent J Suppl 1991; 76: 1-102 (PMID: 1830174).

4. Leigh JP, Miller TR. Occupational illnesses within two national data sets. Int J Occup Environ Health 1998; 4(2): 99-113 (PMID: 10026471).

5. Morse T, Bruneau H, Dussetschleger J. Musculoskeletal disorders of the neck and shoulder in the dental professions. Work 2010; 35(4): 419-429 (PMID: 20448321) (doi: 10.3233/WOR-2010-0979).

6. Akesson I, Johnsson B, Rylander L., Moritz U, Skerfving S. Musculoskeletal disorders among female dental personnel-clinical examination and a 5-year follow-up study of symptoms. Int Arch Occup Environ Health 1999; 72(6): 395-403 (doi: 10.1007/s004200050391) (PMID: 10473839).

7. Hayes M, Cockrell D, Smith DR. A systematic review of musculoskeletal disorders among dental professionals. Int J Dent Hyg 2009; 7(3): 159165 (PMID: 19659711) (doi: 10.1111/j.1601-5037.2009.00395.x).

\section{Authors:}

Hakim A. Larbi - Post-graduate student, Department of pediatric dentistry and orthodontics, Saratov State Medical University, Saratov, Russia;

Dmitry Ye. Suetenkov - MD, PhD, Senior lecturer, Chief of Department of pediatric dentistry and orthodontics, Saratov State Medical University, Saratov, Russia. 